\title{
Naked eye detection of nitric oxide release from nitrosothiols aided by gold nanoparticles $\dagger$
}

\author{
S. Priya, T. Kaviyarasan and Sheela Berchmans* \\ Received 1st December 2011, Accepted 26th January 2012 \\ DOI: 10.1039/c2an16182f
}

In this work we have demonstrated that nitric oxide can be monitored spectrophotometrically using cyclodextrin encapsulated ferrocene. The detection course showed the colour change from yellow to blue which can be detected with the naked eye. Also we describe the catalytic effect of gold nanoparticles in enhancing nitric oxide release from $\mathrm{S}$-nitrosothiols.

Nitric oxide (NO) has attracted considerable attention from chemists and biochemists since it acts as a cell-signalling molecule in humans. NO has several bioregulatory roles such as hormone secretion, vasodilation, bacterial cell adhesion, and neurotransmission and anticarcinogenic properties. ${ }^{1,2}$ Hence probes for detecting NO in the living cell to elucidate its biological roles and for developing NO associated therapies by generating NO in a controlled manner ${ }^{3}$ are highly in demand. The detection of NO in biological systems faces several analytical challenges such as low concentration, very unstable half-life (2-30 s) and high reactivity with oxygen to form nitrite and nitrate in the cells. ${ }^{4}$ There are different analytical methods to determine NO production directly or indirectly. They include electron paramagnetic resonance (EPR) spectroscopy, ${ }^{5}$ fluorescence, ${ }^{6}$ GC$\mathrm{MS},{ }^{7}$ spectrophotometric detection using haemoglobin and via a nitrite azo-coupling reaction ${ }^{8}$ and electrochemical methods. ${ }^{9}$

In this work, we report a spectrophotometric detection of nitric oxide released from triphenylmethane nitrosothiol $\left(\mathrm{Ph}_{3} \mathrm{CSNO}\right)$ using ferrocene encapsulated within the hydrophobic pocket of hydroxypropyl- $\beta$-cyclodextrin $(\mathrm{CD}-\mathrm{Fc})$. Nitrosothiols are a class of NO donors because they occur endogenously as S-nitrosoglutathione. Nitrosothiols (RSNO) have the same physiological property as that of nitric oxide. NO is transported around the body as S-nitroso albumin and they can decompose in vivo generating NO. ${ }^{10}$ Our method of detection is based on the formation of the blue ferrocenyl cation. In the presence of NO, the ferrocenyl cation which is blue in colour shows absorption maximum at $618 \mathrm{~nm}$ (Fig. 1). Hence

Electrodics and Electrocatalysis Division, CSIR-Central Electrochemical Research Institute, Karaikudi, Tamilnadu, 630006, India. E-mail: sheelaberchmans@yahoo.com; Fax: +91 4565 227779; Tel: +91 4565 227551

$\dagger$ Electronic supplementary information (ESI) available: Preparation of chitosan stabilised GNPs, TEM images of GNPs used for controlled release of $\mathrm{NO}$, UV-Vis characterisation of ferrocenyl cation formation in the presence of GNPs, colour change of CD-Fc with respect to time and contact angle studies. See DOI: 10.1039/c2an16182f measurement of absorbance changes at $618 \mathrm{~nm}$ can be used to sense NO. Also we have shown that gold nanoparticles stabilised by two different stabilisers of opposite charges (citrate and chitosan) are able to enhance the release rate of nitric oxide from RSNO. Enhancement in the release rate of NO induced by gold nanoparticles (GNPs) is due to the enhanced affinity of $\mathrm{Ph}_{3} \mathrm{CS}$ towards $\mathrm{Au}$ which prevents disulfide formation.

$$
\begin{gathered}
\mathrm{Ph}_{3} \mathrm{CSNO} \Leftrightarrow \mathrm{Ph}_{3} \mathrm{CS}^{-}+\mathrm{NO} \\
\left.\mathrm{Fc}(\text { yellowish orange })+\mathrm{NO} \Leftrightarrow \mathrm{Fc}^{+} \text {(blue }\right)+\mathrm{NO}^{-} \\
\lambda_{\text {max }}=438 \mathrm{~nm} \\
\lambda_{\max }=618 \mathrm{~nm}
\end{gathered}
$$

$\mathrm{CD}-\mathrm{Fc}, \mathrm{Ph}_{3} \mathrm{CSNO}$ and citrate capped gold nanoparticles were prepared as reported earlier. ${ }^{11-13}$ The size of the citrate capped gold GNPs as determined by TEM was $20 \pm 5 \mathrm{~nm}$ (ESI Fig. Sla $\uparrow$ ). Chitosan stabilised GNPs were prepared without any reducing agent $^{14}$ (see ESI $\dagger$ ). TEM analysis reveals that the size of nanoparticles thus prepared was $50 \pm 6 \mathrm{~nm}$ (ESI Fig. S1b $\dagger$ ).

Fig. 2 shows UV-Vis spectra depicting the changes in the absorbance of ferrocenyl cation with increase in the concentrations of NO from 0 to $40 \mu \mathrm{M}$. Here each addition corresponds to $5 \mu \mathrm{M}$. As the concentration of NO increases the intensity of the peak at $438 \mathrm{~nm}$ decreases and that of the peak at $618 \mathrm{~nm}$ increases. The relationship between the $618 \mathrm{~nm}$ absorption and NO concentration was found to be linear. The inset shows a plot of the intensity of absorption at

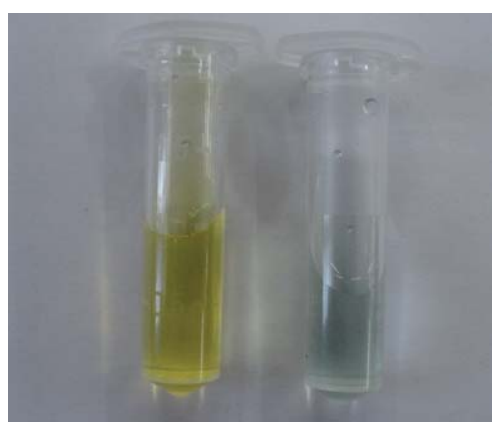

Fig. 1 Colour change observed during ferrocenyl cation formation in the presence of nitric oxide. 


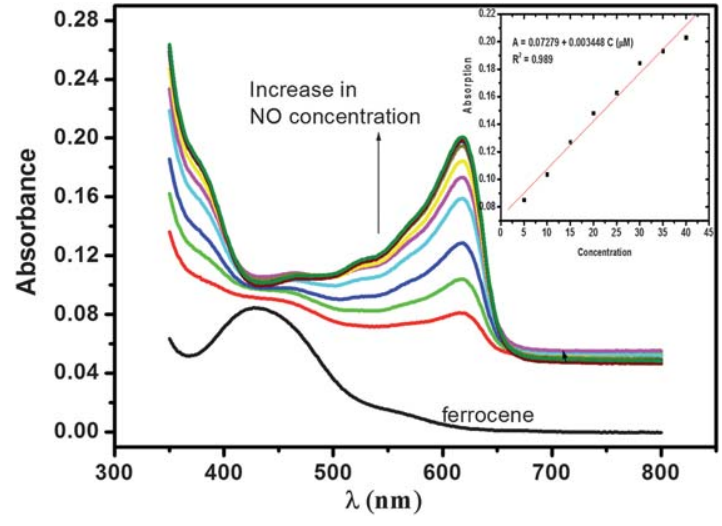

Fig. 2 UV-Vis spectra of $\mathrm{CD}-\mathrm{Fc}$ in the presence of various concentrations of NO. The spectra were recorded at $\mathrm{pH}<3$ in dil. $\mathrm{H}_{2} \mathrm{SO}_{4}$. The concentration of $\mathrm{NO}$ varies from 0 to $40 \mu \mathrm{M}$. Each addition corresponds to $5 \mu \mathrm{M}$. The inset shows a plot of absorption $v$ s. concentration.

$618 \mathrm{~nm} v s$. concentration. Using the absorbance changes at $618 \mathrm{~nm}$ the limit of detection of NO was found to be $600 \mathrm{nM}$ (ESI Fig. S2 $\dagger$ ). Selectivity was studied through the titration experiments with common interference species such as dopamine, ascorbic acid, $\mathrm{NO}_{3}{ }^{-}$ and $\mathrm{H}_{2} \mathrm{O}_{2}$. No colour change was observed and the absorbance at $618 \mathrm{~nm}$ did not show any characteristic change.

The influence of gold nanoparticles (GNPs) on NO released from $\mathrm{Ph}_{3} \mathrm{CSNO}$ was also studied with the help of CD-Fc. An enhancement of NO release rate is observed in the presence of GNPs. The release of NO in the presence of GNPs involves the breaking of the S$\mathrm{N}$ bond in the nitrosothiol and the formation of a $\mathrm{S}-\mathrm{Au}$ bond with the GNP (see Scheme 1).

The gold thiolate $\left(\mathrm{S}-\mathrm{Au}\right.$ ) bond energy is about $40 \mathrm{kcal} \mathrm{mol}^{-1}$ (ref. 15) which is greater than that of the $\mathrm{S}-\mathrm{N}$ bond dissociation energy viz., $20-32 \mathrm{kcal} \mathrm{mol}^{-1} \cdot{ }^{16}$ Hence the $\mathrm{S}-\mathrm{N}$ bond can be easily cleaved in the presence of GNPs favouring S-Au bond formation. The UV-Vis spectrum shows how the ferrocenyl cation formation rate varies with the addition of GNPs to the solution containing $\mathrm{Ph}_{3} \mathrm{CSNO}$ (ESI Fig. S3†).

$$
\mathrm{Ph}_{3} \mathrm{CSNO}+\mathrm{Au} \Leftrightarrow \mathrm{Ph}_{3} \mathrm{CS}-\mathrm{Au}+\mathrm{NO}
$$

$\mathrm{Ph}_{3} \mathrm{CSNO}$ decomposition was carried out under acidic conditions $(\mathrm{pH}<3) .3 \mathrm{mg}$ of $\mathrm{Ph}_{3} \mathrm{CSNO}$ was dispersed in dil. $\mathrm{H}_{2} \mathrm{SO}_{4}$. To this solution aqueous ferrocene and GNP solution were added. Ferrocenyl cation formation was monitored using UV-Vis spectroscopy immediately after adding $\mathrm{Ph}_{3} \mathrm{CSNO}$ (for naked eye detection see ESI Fig. S4†). Fig. 3 depicts the NO release rate in terms of intensity changes of the ferrocenyl cation with respect to time for different concentrations of GNPs. From the figure it is

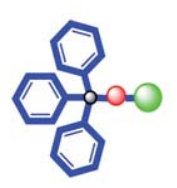

$\mathrm{Ph}_{3} \mathrm{CSNO}$
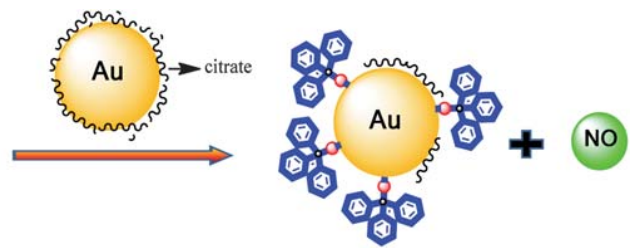

Scheme 1 Schematic showing the influence of gold nanoparticles on nitric oxide release from nitrosothiol.

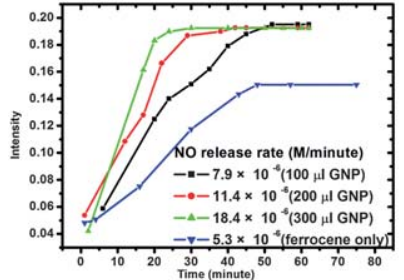

(a)

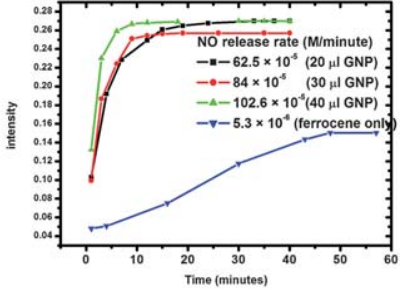

(b)
Fig. 3 Plot of intensity vs. time for ferrocenyl cation formation at 618 $\mathrm{nm}$ in the presence of the (a) chitosan stabilised and (b) citrate stabilised gold nanoparticles of various concentrations.

clear that by increasing the concentration of GNPs, the reaction rate improves to a great extent. Enhanced NO release rates as calculated from the slope of the linear portion of the curves clearly reveal the positive influence of GNPs on NO release. Fig. 3a corresponds to the effect of NO release in the presence of chitosan stabilised GNPs. Kinetic data show that the reaction rate is proportional to GNP concentration. When $100 \mu$ GNPs $(0.0125$ $\mu \mathrm{M} \mathrm{Au})$ of size $50 \mathrm{~nm}$ is added to the nitrosothiol containing solution, the NO release increases by 1.5 times and the saturation occurs within 50 minutes. For additions of 200 and $300 \mu$ GNPs the NO release increases by nearly 2.5 and 3.5 times respectively and the corresponding saturation time was found to decrease to 30 and 20 minutes. Fig. $3 \mathrm{~b}$ corresponds to the enhanced release of NO in the presence of citrate capped gold nanoparticles. $20 \mu \mathrm{l}$ $(0.017 \mu \mathrm{M}$ of $\mathrm{Au})$ addition of this GNP improves the reaction rate to a greater extent (11.8 times). The NO release reaches saturation after 27 minutes. The time required for attaining saturation was found to be reduced to 15 and 9 minutes for 30 and $40 \mu$ of GNPs. The results indicate that the citrate capped nanoparticles with an average size of $20 \mathrm{~nm}$ enhance NO release to a greater extent compared to chitosan stabilised GNPs with an average size of 50 $\mathrm{nm}$. GNPs with $20 \mathrm{~nm}$ size have high surface area-to-volume ratio compared to that of $50 \mathrm{~nm}$ GNPs. Hence a higher number of thiolate groups can replace the citrate capping agents, resulting in an enhanced NO release within a short time interval. Here we have shown that NO release from S-nitrosothiol based systems can be tuned by varying the size and concentration of gold nanoparticles, so that NO release rate can be controlled according to the need. The system was validated using Griess assay. ${ }^{17} \mathrm{Ph}_{3} \mathrm{CSNO}$ and GNPs were placed in oxygenated phosphate buffer, upon which the liberated NO is oxidised to nitrite $\left(\mathrm{NO}_{2}^{-}\right)$. Different sets of the same experiment were conducted and the supernatant from each set was analysed at various time intervals. The supernatant containing $\mathrm{NO}_{2}{ }^{-}$was reacted with $1 \mathrm{wt} \%$ solutions of sulfanilamide and $\mathrm{N}-1-$ naphthylethylenediamine to form an azo compound. By detecting the absorbance at $540 \mathrm{~nm}$ and comparing the results to a calibration curve, the concentration of NO released is deduced. Results were in good agreement with the $\mathrm{CD}-\mathrm{Fc}$ system.

The mechanism of release of NO has been confirmed by absorbance, TEM and contact angle experiments. The replacement of the capping agent by $\mathrm{Ph}_{3} \mathrm{CSNO}$ was confirmed by monitoring the shift of SPR of GNPs. A red shift of the SPR band from $523 \mathrm{~nm}$ to $538 \mathrm{~nm}$ is observed after treating citrate capped GNPs with $\mathrm{Ph}_{3} \mathrm{CSNO}$. ESI Fig. $\mathrm{S} 5 \dagger$ shows the absorbance band before and after ligand exchange. The inset shows the colour change observed during the reaction 

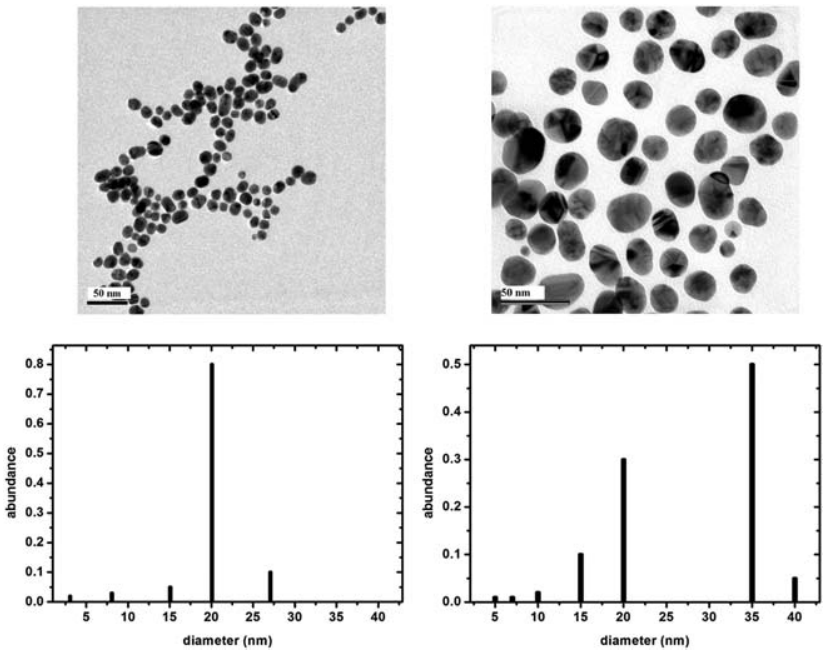

Fig. 4 TEM images of citrate capped GNPs before and after place exchange with $\mathrm{Ph}_{3} \mathrm{CSNO}$ along with the size distribution histogram.

i.e. from purple red to light blue. The shift in the SPR band observed is due to the inter-particle clustering leading to increase in the size of GNPs during the place exchange reaction which is in line with the observation of the TEM images. Fig. 4 shows TEM images and size distribution histograms of GNPs before and after place exchange. TEM analysis demonstrates that the place exchange procedure does induce inter-particle clustering which remains quite well dispersed with a nearly spherical shape. The presence of bulky triphenyl methane groups on the surface of Au cores makes the particles well separated. Mariarita et al. reported similar dispersed nanostructures for platinum nanoparticles after place exchange reaction. ${ }^{18}$

The mechanism of nitric oxide release was also confirmed by contact angle studies, which confirmed the Au-thiolate bond formation during NO release from nitrosothiols (ESI Fig. S6†). A uniform layer of chitosan is formed on a gold plate by a drop casting process and this plate is dipped in the GNP solution for 1 hour followed by air drying. The modified gold plate is then immersed in $\mathrm{Ph}_{3} \mathrm{CSNO}$ dispersed solution for two hours. After drying, contact angle measurement was performed at every stage. The merely chitosan coated plate shows an angle of $88^{\circ}$ and after the incorporation of GNPs it shows an angle of $86^{\circ}$. After treatment with $\mathrm{Ph}_{3} \mathrm{CSNO}$ an angle of $124^{\circ}$ is observed confirming the hydrophobic nature due to $\mathrm{Ph}_{3} \mathrm{CS}-\mathrm{AuGNP}$ bond formation. This experiment clearly indicates the gold thiolate bond formation between the $\mathrm{S}$ atom of the $\mathrm{Ph}_{3} \mathrm{CSNO}$ formed during $\mathrm{NO}$ release from nitrosothiol and the gold nanoparticle.

In summary, we demonstrated a simple technique for detecting NO with the naked eye. This method is validated using Griess assay. We could also demonstrate the enhanced release of NO from nitrosothiols in the presence of GNPs and the dependence of the NO release rate on the size of GNPs.

The author, S. Priya, acknowledges CSIR, New Delhi for granting the financial support for the above work in the form of a junior research fellowship. The authors also acknowledge the funding received from CSIR network project (NWP0035) for this work to be carried out.

\section{Notes and references}

1 (a) R. F. Furchgott, Angew. Chem., Int. Ed., 1999, 38, 1870; (b) L. J. Ignarro, G. M. Buga, K. S. Wood, R. E. Byrns and G. Chaudhuri, Proc. Natl. Acad. Sci. U. S. A., 1987, 84, 9265; (c) R. M. J. Palmer, A. G. Ferrige and S. Moncada, Nature, 1987, 327, 524; (d) L. J. Ignarro, Angew. Chem., Int. Ed., 1999, 38, 1882; (e) F. Murad, Angew. Chem., Int. Ed., 1999, 38, 1857; (f) R. F. Furchgott, Angew. Chem., Int. Ed., 1999, 38, 1870; (g) J. O. Lundberg, E. Weitzberg and M. T. Gladwin, Nat. Rev. Drug Discovery, 2008, 7, 156; (h) D. Fuumura, S. Kashiwagi and R. K. Jain, Nat. Rev. Cancer, 2006, 6, 521.

2 (a) G. Hummel, A. J. Fisher, S. M. Martin, F. Q. Schafer and G. R. Buettner, Free Radical Biol. Med., 2006, 40, 501-506; (b) W. Xu, L. Z. Liu, M. Loizidou, M. Ahmed and I. G. Charles, Cell Res., 2002, 12, 311; (c) B. Mitrovic, L. J. Ignarro, H. V. Vinters, M. A. Akerms, I. Schmid and C. Uittenbogaart, Neuroscience, 1995, 65, 531-534; (d) Y. Hou, J. Wang, P. R. Andreana, G. Cantauria, S. Tarasia, L. Sharp, P. G. Braunschweiger and G. Wang, Bioorg. Med. Chem. Lett., 1999, 9, 2255-2260.

3 P. G. Wang, M. Xiang, X. Tang, X. Wu, Z. Wen, T. Cai and A. J. Janczuk, Chem. Rev., 2002, 102, 1091.

4 (a) J. R. Lancaster, Jr, Nitric Oxide, 1997, 1, 18-30; (b) M. Feelisch and J. S. Stamler, Methods in Nitric Oxide Research, John Wiley \& Sons, Ltd, Chichester, UK, 1996; (c) H. Hong, J. Sun and W. Cai, Free Radical Biol. Med., 2009, 47, 684-698.

$5 \mathrm{H}$. Fuji and L. J. Berliner, In Vivo EPR (ESR) Theory and Application, in Biological and Magnetic Resonance, ed. L. J. Berliner, Kluwer Academic/Plenum Publishers, New York, 2003, vol. 18 , ch. 14 , pp. 381-402.

6 T. P. Misko, R. J. Schilling, D. Selvemini, W. M. Moore and M. G. Currie, Anal. Biochem., 1993, 214, 11-16.

7 R. M. J. Palmer, D. S. Ashton and S. Moncada, Nature, 1988, 333, 664.

8 D. S. Bredt and S. H. Snyder, Proc. Natl. Acad. Sci. U. S. A., 1989, 86, 9030

9 (a) B. A. Patel, M. Arundell, K. H. Parker, M. S. Yeoman and D. O'Hare, Anal. Chem., 2006, 78, 7643-7648; (b) A. Pailleret, J. Oni, S. Reiter, S. Isik, M. Etienne, F. Bedioui and W. Schuhmann, Electrochem. Commun., 2003, 5, 847-852; (c) S. Isik, M. Etienne, J. Oni, A. Blochl, S. Reiter and W. Schuhmann, Anal. Chem., 2004, 76, 6389-6394; (d) S. Borgmann, I. Radtke, T. Erichsen, A. Blochl, R. Heumann and W. Schuhmann, ChemBioChem, 2006, 7, 662-668; (e) S. Isik and W. Schuhmann, Angew. Chem., Int. Ed., 2006, 45, 7451-7454.

10 P. R. Myers, R. L. Minor, R. Guerra, J. N. Bates and D. G. Harrison, Nature, 1990, 345, 161-166.

11 (a) T. Mary Vargheese and S. Berchmans, Electrochim. Acta, 2006, 52, 562-577; (b) S. Varatharajan, K. Sathish Kumar, S. Berchmans, R. Amutha, P. V. Kiruthiga and K. Pandima Devi, Analyst, 2010, 135, 2348-2354.

12 N. Arulsamy, D. S. Bohle, J. A. Butt, G. J. Irvine, P. A. Jordan and E. Sagan, J. Am. Chem. Soc., 1999, 121, 7115-7123.

13 J. J. Storhoff, R. Elghanian, R. C. Mucic, C. A. Mirkin and R. L. Letsinger, J. Am. Chem. Soc., 1998, 120, 1959-1963.

14 Y. Haizhen Huang and Y. Xiurong, Biomacromolecules, 2004, 5, $2340-2346$.

15 (a) A. Ulman, Chem. Rev., 1996, 96, 1533-1554; (b) M. D. Bartberger, J. D. Mannion, S. C. Powell, J. S. Stamler, K. N. Houk and E. J. Toone, J. Am. Chem. Soc., 2001, 123, 8868-8869.

16 (a) J. M. Lu, J. M. Wittbrodt and K. Wang, J. Am. Chem. Soc., 2001, 123, 2903-2904; (b) T. B. Patricia, R. L. Laura, S. S. Marcos, P. Hervies, A. C. Miguel, A. A. Ramon and M. L. Luis, ACS Appl. Mater. Interfaces, 2009, 1, 56-59.

17 (a) E. M. Hetrick and M. H. Schoenfisch, Annu. Rev. Anal. Chem., 2009, 2, 409-433.

18 (a) B. Mariarita, T. Maria Sciortino, D. Zaccaria, M. Antonino and S. Salvatore, J. Mater. Chem., 2008, 18, 5531; (b) Y. J. Hong, L. Yang, J. Z. Xue, L. Han, L. Bo Du, Q. Tian and C. X. Yuan, J. Am. Chem. Soc., 2009, 131, 40-41; (c) B. Mariarita, T. S. Maria, Z. Daniela, M. Antonino and S. Salvatore, J. Mater. Chem., 2008, 18, 5531-5536. 